\title{
PENGARUH APLIKASI TINDAKAN KEPERAWATAN GENERALIS: ANSIETAS PADA PASIEN PENYAKIT GINJAL KRONIK
}

\author{
Eneng Elisnawati ${ }^{1}$, Ice Yulia Wardani ${ }^{2}$ \\ ${ }^{1}$ Fakultas Ilmu Keperawatan, Universitas Indonesia, Kampus FIK UI Depok, 16424, Indonesia \\ ${ }^{2}$ Departemen Keperawatan Jiwa, Universitas Indonesia, Kampus FIK UI Depok, 16424, Indonesia \\ E-mail:enengelisnawati@gmail.com
}

\begin{abstract}
ABSTRAK
Pola hidup yang tidak sehat merupakan salah satu penyebab terjadinya penyakit ginjal kronik. Masyarakat perkotaan sangat rentan memiliki pola hidup tidak sehat, yang pada akhirnya dapat menyebabkan penyakit ginjal kronik. Penyakit ginjal kronik merupakan suatu keadaan dimana ginjal mengalami kerusakan yang bersifat permanen yang akan berdampak pada penurunan fungsi dari ginjal. Perubahan fisik yang terjadi pada penderita penyakit ginjal kronik terkait dengan tanda dan gejala dari keparahan penyakit yang dialami tentu akan berpengaruh pada kondisi psikososial pasien. Masalah psikososial yang muncul pada penderita penyakit ginjal kronik yang dirawat di Rumah Sakit adalah Ansietas. Karya Ilmiah Akhir ners ini bertujuan untuk menggambarkan asuhan keperawatan anisetas pada pasien yang mengalami penyakit ginjal kronik khusunya dengan teknik relaksasi. Pasien yang mampu mengatasi rasa cemasnya akan dapat meningkatkan keefektifan dari pengobatan fisik yang sedang dijalani. Sehingga, diperlukannya peran perawat dalam memberikan asuhan keperawatan psikososial agar masalah ansietas tidak menimbulkan dampak yang merugikan bagi klien.
\end{abstract}

Kata Kunci : Ansietas, Penyakit Ginjal Kronik, teknik relaksasi

\section{EFFECT OF APPLICATION OF GENERALIST NURSING ACTION: ANSIETAS ON CHRONIC POSTED DISEASE PATIENTS}

\begin{abstract}
Unhealthy lifestyle caused of chronic kidney disease. Urban communities are particularly vulnerable to unhealthy lifestyles, which can lead to chronic kidney disease. Chronic kidney disease is a condition which the kidney are permanently damaged and ultimately have an impact to the function of the kidney. Physical changes that occur in patients with chronic kidney disease associated with signs and symptom's the severity of the disease. It will certainly affect the psychosocial condition of patients. Psychosocial problems that arise in hopitalized patients with chronic kidney is anxiety. This Scientific works aims to describe the nursing care of anxiety in patients with Chronic Kidney disease especially with relaxation techniques. Patients who are able to overcome their anxiety will improve the effectiveness of the physical treatments that are being undertaken. Thus, the nurse's role in providing psychosocial nursing care is necessary so that anxiety problems do not cause adverse impact to the patient.
\end{abstract}

Keywords: Axiety, Chronic Kidney Disease, Relaxation technique

\section{PENDAHULUAN}

Masyarakat yang tinggal di wilayah perkotaan atau disebut dengan masyarakat perkotaan merupakan suatu bentuk dari adanya perubahan dinamika sosial pada suatu wilayah. Perubahan tersebut dapat terjadi akibat adanya perubahan sistem ekonomi dan perubahan sejarah wilayah tersebut seiring berjalanya dengan waktu dapat mempengaruhi budaya yang bersifat tradisional menjadi lebih modern (Urban Partnerships Foundation, 2014). Perubahan yang terjadi dapat berpengaruh pada perilaku promosi kesehatan di wilayah perkotaan. Promosi kesehatan yang cukup buruk di lingkungan perkotaan akan mempengaruhi gaya hidup masyarakat perkotaan, yang merupakan penyebab utama terjadinya masalah kesehatan pada masyarakat perkotaan (World Health Organization, 2010).

Salah satu jenis penyakit tidak menular yang dapat terjadi pada masyarakat perkotaan adalah Penyakit Ginjal Kronik atau Chronic Kidney Disease (CKD) (Hall, et al., 2010). Penyebab terjadinya penderita penyakit ginjal kronik pada masyarakat perkotaan terutama 
dikarenakan adanya sanitasi air yang masih kurang, masih kurangnya pengetahuan masyarakat perkotaan terkait dengan pola hidup yang sehat, sehingga masih salah kaprah dalam mengkonsumsi minuman tertentu yang pada akhirnya dapat merujuk pada terjadinya penyakit ginjal kronik (Garcia \& Jha, 2015).

National Center for Chronic Disease Prevention and Health Promotion (2014), menyatakan bahwa terdapat 20 juta orang di Amerika Serikat yang merupakan penderita penyakit ginjal kronik dengan faktor penyebab yang paling tinggi adalah diabetes. Indonesia sendiri memiliki angka penderita penyakit ginjal kronik yang cukup signifikan yaitu sebanyak 504.248 jiwa (Riskesdas, 2013). Penyakit Ginjal Kronik atau Chronic Kidney Disease (CKD) merupakan gangguan fungsi renal yang progresif dan irreversible dimana kemampuan tubuh gagal untuk mempertahankan metabolisme dan keseimbangan cairan dan elektrolit dimana pada akhirnya menyebabkan uremia (retensi urea dan sampah nitrogen lain dalam darah) (Smeltzer, et al., 2010).

Ansietas merupakan salah satu masalah psikososial yang dapat terjadi pada siapapun, tidak terkecuali pada pasien yang di rawat di Rumah Sakit. Ansietas pada pasien yang dirawat di Rumah Sakit merupakan hal yang bisa terjadi diakibatkan dari perubahan kondisi sehat menjadi sakit. Berdasarkan penelitian yang dilakukan di Brazil pada satu rumah sakit dengan jumlah responden penelitian sebanyak 282 pasien, dimana terdata sebanyak 33,7\% pasien mengalami ansietas (Gullich, et al., 2013).

Kondisi fisik yang dipengaruhi oleh penyakit ginjal kronik yang diderita akan dapat berpengaruh pada keadaan psikologis dari penderitnya, dimana dalam hal ini terdapat hubungan yang bermakna antara persepsi individu terhadap penyakitnya dan kondisi psikologis penderita penyakit ginjal kronik. Perasaan cemas yang tinggi hingga dapat menyebabkan depresi merupakan kondisi psikologis pasien dengan penyakit ginjal kronik pada stadium 3-5 (Knowles, et al., 2014). Selain itu, penelitian yang dilakukan oleh $\mathrm{Wu}$, et al., (2016) dengan metode interview pada 15 penderita penyakit ginjal kronik stadiun akhir, didapatkan data bahwa rasa cemas yang diakibatkan oleh persepsi penderita terhadap penyakitnya merupakan temuan yang signifikan dibandingkan dengan yang diakibatkan oleh kondisi nyata tubuh penderita penyakit ginjal kronik (Wu, et al., 2016).

Cemas atau ansietas adalah salah satu permasalahan psikososial yang kerap muncul di ruang Antasena RS. Marzoeki Mahdi Bogor. Hasil observasi yang dilakukan selama tujuh pekan di ruang rawat Antasena memberikan gambaran mengenai asuhan keperawatan terkait permasalahan ansietas yang sudah sering ditegakkan sebagai diagnosis keperawatan, tetapi masih perlu peningkatan dan pengembangan. Perawat ruang Antasena sudah dapat menerapkan pelaksanaan intervensi cemas dalam berinteraksi dengan klien-klien dengan cemas meskipun belum optimal. Penulis tertarik untuk melakukan asuhan keperawatan secara komprehensif terhadap klien yang mengalami cemas, yaitu pada Ibu E dengan Penyakit Ginjal Kronik yang dirawat di ruang Antasena RS. $\mathrm{H}$. Marzoeki Mahdi Bogor.

\section{METODE}

Asuhan keperawatan dilakukan berdasarkan tahapan proses keperawatan, mulai dari pengkajian, analisis data, penegakkan diagnosis, perencanaan intervensi keperawatan, implementasi, serta evaluasi. Asuhan keperawatan pada klien ansietas dengan penyakit ginjal kronik dilakukan dengan pendekatan masalah fisik dan psikososial. Namun, asuhan keperawatan yang diberikan penulis lebih fokus kepada masalah psikososial yang dikaitkan dengan masalah fisik klien. Selanjutnya, penulis menganalisis kesenjangan antara teori dan hasil dari asuhan keperawatan yang telah diberikan.

\section{HASIL}

Ibu E berusia 30 tahun datang ke IGD RSMM Bogor pada tanggal 4 Mei 2017 dengan keluhan mengalami sesak napas selama satu hari sebelum masuk ke Rumah Sakit. Selain itu, klien mengatakan bahwa sejak satu bulan yang lalu dirinya sudah mengalami bengkak pada ekstremitas atas dan bawahnya. Pada hari itu juga, Ibu $\mathrm{E}$ dipindahkan ke ruang perawatan Antasena kamar 4. Klien masuk dengan diagnosis medis Penyakit Ginjal 
Kronik. Pengkajian dilakukan pada tanggal 5 Mei 2017.

Pengkajian psikososial didapatkan yaitu, klien mengatakan bahwa dirinya merasa cemas dengan kondisi yang dialaminya saat ini dimana dia sangat takut jika dirinya tidak dapat sembuh dan berkumpul dengan keluarganya lagi. Selain itu, klien mengatakan bahwa dirinya khawatir dengan kondisi anaknya yang saat ini dirawat oleh saudaranya di rumah. Klien terlihat banyak melamun ketika di ruang rawat, klien tampak cemas ketika menceritakan soal kondisinya dan klien menangis pada saat menceritakan tentang anaknya.

Ibu E mengatakan bahwa dirinya tidak begitu dekat dengan saudara kandungnya. Klien dekat dengan suaminya. Klien merupakan tipe orang yang tidak menceritakan masalah atau persoalan yang sedang dihadapinya pada orang lain. Klien mengatakan suka memikirkan permasalahannya sendiri, termasuk pada saat merasakan tubuhnya sering lemas. Klien tidak menceritakan pada siapapun. Klien dan keluarga juga tidak rutin dalam memeriksakan kesehatannya di pusat pelayanan kesehatan. Keluarga hanya memeriksakan kesehatan saat klien sudah tidak dapat menahan sakitnya. Hal yang terjadi pada kondisi Ibu E, klien dibawa ke RS Dhuafa setelah kondisi ginjalnya mengalami pembesaran, adanya edema pada kaki dan tanganya serta kondisi klien yang merasa lemas dan sesak napas.

Keadaan umum klien tampak lemas, selama di rawat di RSMM, klien dibantu oleh ibunya dalam perawatan diri sehari-hari. Klien mengatakan bawa dirinya ingin sembuh dan dapat berkumpul dengan keluarganya kembali. Klien juga mengatakan dengan kondisinya yang lemas seperti ini klien tidak dapat beraktifitas. Klien mengatakan semenjak di rawat di RSMM nafsu makanya menjadi menurun dan klien tampak sedih ketika menceritakan tentang kondisinya. Pada saat dilakukan pengkajian dan penulis menanyakan tentang pembatasan cairan pada klien, ternyata klien dan keluarga sebelumnya sudah diberitahu namun lupa jumlah tepatnya cairan yang boleh dikonsumsi oleh klien.

Pada pengkajian inspeksi, terlihat adanya edema derajat 2 pada ekstremitas bawah dan atas klien. Berdasarkan hasil pemeriksaan laboratorium pada tanggal 04 Mei 2017 didapatkan data $\mathrm{Hb}$ : 9,8 g/dl, $\mathrm{Ht}: 29 \%$, Leukosit $13.61 \times 10^{3} / \mathrm{UL}$, Albumin: $2,6 \mathrm{~g} / \mathrm{dl}$, Ureum:122,0 mg/dl dan kreatinin: $2,00 \mathrm{mg} / \mathrm{dl}$. Sedangkan pada hasil pemeriksaan radiologi pada tanggal 05 Mei 2017 didapatkan kesan adanya gangguan pada parenchimal kedua ginjal grade III dengan asites

Berdasarkan hasil pengkajian dan analisis data, didapatkan diagnosis keperawatan: kelebihan volume cairan tubuh, ansietas dan ketidakberdayaan. Masalah keperawatan ansietas ditegakkan berdasarkan NANDA 2015-2017. Tingkat ansietas klien disesuaikan dengan teori tingkatan ansietas berdasarkan tanda dan gejalanya (Viedebeck, 2008).

Tindakan keperawatan yang difokuskan pada masalah ansietas, berupa mengenalkan klien tentang ansietas yang dimiliki, teknik relaksasi napas dalam dan distraksi, teknik hipnosis lima jari, serta kegiatan spiritual. Tindakan keperawatan dilakukan selama tujuh hari perawatan. Tindakan keperawatan yang diberikan pada klien dimulai dengan menjalin hubungan saling percaya, penulis mencoba memulai perbincangan dengan mengucapkan salam terapeutik. Klien membalas salam yang diberikan oleh penulis. Penulis lalu mengajak klien untuk berkenalan dan klien senang dipanggil Ibu E. Sebelum perbincangan dimulai, penulis menjelaskan terlebih dahulu mengenai tujuan dilakukannya intervensi. Pertemuan hari pertama, klien belum menunjukkan tanda dan gejala dari masalah psikososial ansietas. Klien baru mulai menceritakan apa yang dirasakannya pada saat ini, setelah merasa dekat dengan penulis. Klien mengatakan bahwa dirinya merasa cemas dengan kondisi yang dialaminya saat ini, dimana dia sangat takut jika dirinya tidak dapat sembuh dan berkumpul dengan keluarganya lagi. Selain itu, klien mengatakan bahwa dirinya khawatir dengan kondisi anaknya yang saat ini dirawat oleh saudaranya di rumah. Klien terlihat banyak melamun ketika di ruang rawat, klien tampak cemas ketika menceritakan soal kondisinya dan klien menangis pada saat menceritakan tentang anaknya.

Pertemuan kedua, klien bersama penulis melatih kembali teknik tarik napas dalam yang 
telah diajarkan pada pertemuan sebelumnya. Selain itu, penulis juga mengkaji ulang kondisi klien terkait dengan rasa cemas yang dia ceritakan pada pertemuan sebelumnya. Klien mngatakan bahwa dirinya sering melatih teknik tarik napas dalam ketika dirinya merasa cemas. Hal tersebut dia katakan membuat dirinya merasa lebih tenang. Namun, klien mengatakan bahwa dirinya terkadang masih mengkhawatirkan kondisinya dan kondisi anaknya di rumah. Kemudian, dilakukan latihan teknik spiritual untuk menurunkan rasa cemas klien. Klien yang beragama muslim mampu melakukan dzikir, namun klien mengatakan bahwa dirinya belum siap untuk melakukan sholat.

Pada pertemua ketiga, penulis melakukan pengkajian ulang terhadap rasa cemas yang klien miliki terkait dengan kondisinya dan kondisi anaknya di rumah. Klien mengatakan merasa jauh lebih tenang saat ini, walaupun terkadang masih suka melamun memikirkan kondisinya saat ini. Kemudian dilakukan latihan teknik hipnosis lima jari. Pada saat setelah dilakukan latihan teknik hipnosis lima jari klien mengatakan bahwa dirinya merasa nyaman dan mengantuk. Namun ketika ditanyakan perasaanya bagaimana Ibu $\mathrm{E}$ menangis dan mengatakan bahwa dirinya ingin sembuh dan ingin dapat berkumpul lagi dengan keluarganya. Penulis meengatakan bahwa Ibu $\mathrm{E}$ harus tetap semangat dan terus berjuag demi keluarganya serta fokus pada pengobatan yang sedang dijalani sekarang.

\section{PEMBAHASAN}

Selama tujuh hari perawatan, klien mendapatkan tindakan keperawatan berupa strategi pelaksanaan ansietas secara lengkap. Selain itu, intervensi keperawatan terkait dengan masalah keperawatan kelebihan volume cairan pada klien juga telah dilakukan. Masalah retensi cairan pada penderita penyakit ginjal kronik tidak boleh diabaikan dimana, seiring berjalannya waktu dengan penurunan fungsi ginjal secara terus menerus akan menyebabkan retensi cairan yang berlanjut (Smeltzer, 2010). Penurunan fungsi ginjal dan juga peningkatan retensi cairan dapat terlihat dari hasil laboratorium. Berdasarkan hasil pemeriksaan laboratorium pada Ibu E yang dilakukan pada tanggal 04 Mei 2017 didapatkan data Hb: 9,8 g/dl, Ht: 29 $\%$, Leukosit $13.61 \times 10^{3} / \mathrm{UL}$, Albumin: 2,6 $\mathrm{g} / \mathrm{dl}$, Ureum:122,0 mg/dl dan kreatinin: 2,00 $\mathrm{mg} / \mathrm{dl}$. Pada hasil pemeriksaan terlihat adanya penurunan fungsi ginjal dari penurunan fungsi ginjal dari peningkatan kreatinin dan ureum didalam darah. Seharusnya sebagai zat akhir metabolik tubuh, urum dan kreatinin dibuang melalui urin (Black \& Hawks, 2014). Penurunan albumin menyebabkan terjadinya kondisi hipoalbumin dimana pada keadaan ini akan terjadi peningkatan membran permiabel pembuluh darah sehingga plasma darah akan dapat berpindah ke jaringan interstisial yang pada akhirnya menyebabkan edema ekstremitas pada Ibu E.

Kondisi psikososial Ibu E yang mengalami ansietas dapat dipengaruhi oleh berbagai faktor. Berdasarkan hasil penelitian, faktor gender, usia dan jenis penyakit yang diderita pada pasien yang dirawat di Rumah Sakit berpengaruh terhadap tingkat ansietas pasien tersebut. Pasien yang di rawat di Rumah Sakit dan terdiagnosis mengalami penyakit kronik memiliki prevalensi ansietas yang lebih tinggi (Gullich, et al., 2013). Hal tersebut sejalan dengan yang dialami oleh Ibu E dimana Ibu E terdiagosis penyakit ginjal kronik, yang mana sangat mempengaruhi kondisinya dan kualitas hidupnya.

Usia dan gender pada penderita penyakit ginjal kronik merupakan faktor yang dapat mempengaruhi tingkat kecemasan pada klien (Gullich, et al., 2013). Hal tersebut sejalan dengan hasil penelitian yang dilakukan oleh Gullich, et al. (2013) pada 282 pasien didapatkan data bahwa rentang usia 18-39 tahun merupakan rentang usia dimana sebanyak $41.30 \%$ mengalami ansietas sedangkan sisanya terbagi pada rentang usia 40-59 tahun dan $>60$ tahun dengan total keseluruhan pasien yang mengalami ansietas adalah 95 pasien (Gullich, et al., 2013).

Selain faktor usia, pada penelitian yang dilakukan oleh Rodrigo, et al., juga menemukan bahwa gender akan mempengaruhi tingkat ansietas seseorang. Berdasarkan hasil penelitian didapatkan 57\% dari responden penelitian merupakan wanita (Rodrigo, et al., 2013). Selain itu, Gullich, et al. (2013), juga menemukan bahawa wanita cenderung mengalami ansietas dibandingkan dengan pria. Hal ini dapat terjadi karena wanita cenderung lebih mudah berespon 
terhadap hal yang terjadi pada tubuhnya (Gullich, et al., 2013). Sedangkan pria akan cenderung untuk tidak memperlihatkan rasa cemas yang dialaminya (Gullich, et al., 2013). Ibu E yang berjenis kelamin wanita memang mengalami ansietas dan hal tersebut sejalan dengan penelitian yang dilakukan oleh Rodrigo, et al. (2013) dan Gullich, et al. (2013).

Cemas yang dilami oleh Ibu E juga diakibatkan dari pemikiran-pemikiran negatif tentang kondisinya yang mana sebetulnya efek samping dari penyakit yang dideritanya belum mencapai pada tahap tersebut. Hal tersebut sejalan dengan yang di ungkapkan oleh Knowles, et al. (2014) bahwa terdapat hubungan yang bermakna antara persepsi individu terhadap penyakitnya dengan kondisi psikologis pada penderita penyakit ginjal kronik (Konwles, et al., 2014).

Rasa cemas atau ansietas yang dialami oleh penderita penyakit ginjal kronik yang berada pada stadium akhir diakibatkan dari persepsi penderita terhadap penyakitnya yang merupakan temuan yang signifikan. Hal tersebut dibandingkan dengan yang diakibatkan oleh kondisi nyata tubuh penderita penyakit ginjal kronik $(\mathrm{Wu}$, et al., 2016). Penemuan tersebut sejalan dengan hasil pengkajian dari penyebab ansietas yang dialami oleh Ibu E, dimana dia lebih cenderung untuk memikirkan hal-hal negatif yang mungkin terjadi terkait dengan kondisinya saat ini, walaupun sebenarnya belum terjadi.

Klien mengatakan bahwa dirinya sangat kahawatir dengan kondisinya sekarang ini dia menjadi tidak bisa mengurus anaknya yang berada di rumah dititipkan pada tantenya. Sejalan dengan penelitian yang dilakukan oleh Kader, et al. (2009), didapatkan data bahwa pasien yang berada pada stadium akhir penyakit ginjal kronik memiliki stresor yang berasal dari tanda dan gejala penyakitnya yang dapat mempengaruhi kondisi psikologis individu tersebut (Kader, et al., 2009)

Pada kasus Ibu E, klien mengalami ansietas sedang yang mulai menuju pada tahap berat. Ibu E dikategorikan pada tahap sedang diakrenakan menurut Videbeck (2008), tanda dan gejala yang Ibu E alami seperti berkringat, ketegangan otot sedang, lapang persepsi menurun, rentang perhatian menurun, kemampuan dalam menyelesaikan masalah menurun, kepercayaan diri goyah serta ada pengungkapan bahwa dirinya merasa tidak nyaman dengan kondisinya saat ini merupakan tanda dan gejala dari ansietas sedang. Namun, kondisi klien yang mulai terbagi-bagi pemikiranya pada anak dan suami serta pada proses kesembuhanya, adanya pengungkapan rasa takut dan terkadang tampak bingung merupakan tanda dan gejala pada ansietas berat.

Penemuan yang didapatkan pada kasus yang dikelola yaitu Ibu E yang mengalami tingkat ansietas sedang-berat sejalan dengan penelitian yang dilakukan oleh Rodrigo, et al. (2013) pada 100 orang penderita penyakit ginjal kronik, didapatkan data sebanyak $52 \%$ pasien mengalami ansietas berat, $27 \%$ pasien mengalami ansietas sedang dan sisanya mengalami ansietas ringan (Rodrigo., et al., 2013). Pada akhirnya hasil tersebut dapat membantu perawat untuk melakukan intervensi keperawatan yang sesuai dengan masalah psikosoial yang klien alami.

Penulis dan klien mendiskusikan tentang masalah yang dihadapi klien. Kemudian dilakukan latihan psikomotor yang pertama untuk mengatasi rasa cemas klien melalui teknik relaksasi. Berdasarkan penelitian yang dilakukan oleh Harwood, et al. (2008), mengemukakan bahwa penggunaan teknik relaksasi yang dilakukan penderita penyakit ginjal kronik bermanfaat dalam menurunkan kecemasan klien, mengurangi nyeri, insomnia dan kelelahan (Harwood, et al., 2008).

Selain teknik relaksasi napas dalam, penulis juga melakukan latihan psikomotor yang kedua berupa teknik distraksi dengan cara mendiskusikan tentang isi buku yang sedang klien baca. Selain membaca, klien juga senang mendengarkan musik, sehingga saya menganjurkan klien untuk mndengarkan musik dengan tempo yang pelan agar membuat dirinya merasa nyaman. Hal tersebut sejalan dengan penelitian yang dilakukan oleh Suhartini (2008), ditemukan bahwa terapi musik efektif dalam menurunkan perubahan respon fisiologis terhadap kecemasan pada pasien yang dirawat di ruang rawat intensif (Suhartini, 2008). Penelitian lain yang dilakukan oleh Widerhold, et al. (2014) 
menemukan bahwa Virtual Theraphy yang termasuk dalam salah satu teknik distraksi, efektif dalam menurunkan kecemasan dan meningkatkan strategi koping yang positif pada pasien yang dirawat inap (Widerhold, et al., 2014).

Kemudian, dilakukan latihan teknik spiritual untuk menurunkan rasa cemas klien. Pendekatan agama merupakan salah satu bentuk dari koping adaptif yang dimiliki oleh seorang individu (Carver, 2013). Berdasarkan hasil penelitian, peningkatan iman akan mengingkatkan persepsi penderita penyakit ginjal kronik bahwa masih ada Sang Pencipta yang lebih berhak atas diri mereka, sehingga tidak ada persepsi negatif pada Sang Pencipta atas kondisinya saat ini (Finnegan-John \& Thomas, 2013). Klien yang beragama muslim mampu melakukan dzikir, namun klien mengatakan bahwa dirinya belum siap untuk melakukan sholat.

Kemudian dilakukan latihan teknik hipnosis lima jari. Keefektifan penggunaan hipnosis lima jari dalam menurunkan ansietas pada pasien dengan penyakit ginjal kronik telah dibuktikan oleh penelitian yang dilakukan oleh Untas, et al. (2013). Selain menurunya ansietas, penurunan rasa lelah akibat dari menurunya kondisi fisik serta berkurangnya insomnia juga terdata pada responden dalam penelitian ini (Untas, et al., 2013). Pada saat setelah dilakukan latihan teknik hipnosis lima jari klien mengatakan bahwa dirinya merasa nyaman dan mengantuk. Namun, ketika ditanyakan perasaanya bagaimana Ibu $\mathrm{E}$ menangis dan mengatakan bahwa dirinya ingin sembuh dan dapat brkumpul lagi dengan keluarganya. Penulis meengatakan bahwa Ibu E harus tetap semangat dan terus berjuang demi keluarganya.

Pemberian terapi tidak hanya dilakukan oleh perawat generalis, namun juga dilakukan oleh perawat spealis. Tindakan keperawatan yang dilakukan oleh perawat spesialis adalah Cognitive Behaviour Theraphy. Hal tersebut sejalan dengan penelitian yang dilakukan oleh Valsaraj, et al. (2016) didapatkan data bahwa psikoterapi salah satunya adalah Cognitive Behaviour Theraphy efektif dalam mnurunkan ansietas pada penderita ginjal kronik yang mengalami cemas akibat dari kekhatiran terhadap kondisinya (Vasaraj, et al., 2016).
Pada akhirnya dapat meningkatkan keefektifan intervensi keperawatan terhadap masalah fisik yang dialami oleh responden.

\section{SIMPULAN DAN SARAN Simpulan}

Asuhan keperawatan yang dilakukan pada klien yang kooperatif dan aktif, ruang perawatan yang nyaman dan tenang, penulis yang mampu membina hubungan saling percaya dan mendengarkan masalah klien, serta kolaborasi dengan mahasiswa residensi dalam pemberian psikoterapi dapat menurunkan tanda dan gejala ansietas pada klien dengan penyakit ginjal kronik yang dialminya.

\section{Saran}

Peran perawat dalam memberikan asuhan keperawatan psikososial sangat diperlukan agar masalah ansietas tidak menimbulkan dampak yang merugikan bagi klien.

\section{DAFTAR PUSTAKA}

Black, J. M., \& Hawks, J. H. (2014). MedicalSurgical Nursing: Clinical Management for Positive Outcomes (8th ed.). Singapore: Elsevier (Singapore) Pte Ltd.

Carver, C.S. (2013). Cope Inventory. Measurement Database for The Social Science. 17 Juni 2017. www.midss.ie

Finnegan-John, J. \& Thomas, V. (2013). The psychosocial experience of patients with end-stage renal disease and its impact on quality of life: findings from a needs assessment to shape a service. SRN Nephrology .8.DOI: 10.5402/2013/308986.

Garcia \& Jha. (2015). Chronic kidney disease i disadvantages populations. Indian Journal Nephrology, 25(2), 65-69. doi: 10.4103/0971-4065.150078

Gullich, L., et al. (2013). Prevalence of patients admitted to a university hospital in southern Brazil and associated factors. Rev Bras Epidemol, 16 (3), 644-657.

Hall., Choi., Chertow \& Bindman. (2010). Chronic kidney disease in urban poor. 
Clinical Journal Social Nephrology, 5(5), 825-835. doi: 10.2215/CJN.09011209

Hardwood, L., et al. (2008). Stressors and coping in individuals with chronic kidney disease. Nephrology Nursing Journal.

Kader, A., Mark, L.U. \& Steven, D. (2009). Symptom burden, depression, and quality of life in chronic and end-stage kidney disease. Clinical Journal American Social Nephrology, 4 (6): 1057-1064.

DOI: 10.2215/CJN.00430109

Knowles, et al. (2014). Exploring the relationships between health status, illness perceptions coping strategies and psychological morbidity in a chronic kidney disease cohort. Am $J$ Med Sci. 348 (4), 271-276.

National Center for Chronic Disease Prevention and Health Promotion. (2014). National Chronic Kidney Disease Fact Sheet 2014. Diunduh dari https://www.cdc.gov/diabetes/pubs/pdf /kidney_factsheet.pdf

Riskesdas. (2013). Riset Kesehatan Dasar 2013. Diunduh dari http://www.depkes.go.id/resources/do wnload/general/Hasil\%20Riskesdas\% 202013.pdf

Rodrigo, et al. (2013). Symptoms of anxiety among patients with chronic kidney disease in Sri Lanka. Saudi Journal of Kidney Disease and Transplantation, 24(6), 1256-1257.

Smeltzer, S. C., Bare, B. G., Hinkle, J. L., \& Cheever, K. H. (2010). Brunner \&Suddarth's textbook of medicalsurgical nursing (12th ed.). Philadepldphia: Lippincott Williams \& Wilkins.

Suhartini. (2008). Terapi Musik, Teori dan Aplikasi. Jogjakarta: Galangpress.

Untas, et al. (2013). The effects of hypnosis on anxiety, depression, fatigue, and sleepiness in people undergoing hemodialysis: a clinical report. Int $J$ Clin Exp Hypn. 61(4):475-83. DOI: 10.1080/00207144.2013.810485.

Urban Partnership Foundation. (2014). Urban Society. Diakses dari http://www.ombudsman.gov.ph/UNDP 4/wp-content/uploads/2012/12/Chap03.-Urban-Society-30Nov06-UPF.pdf

Valsaraj, B., Bhat, S., \& Latha, K. (2016). Cognitive behaviour therapy for anxiety and depression among people undergoing haemodialysis: a randomized control trial. Journal of Clinical and Diagnostic Research. 10(8), 06-10. DOI: $10.7860 / \mathrm{JCDR} / 2016 / 18959.8383$

Videbeck (2008). Psychiatric mental health nursing. Philadelpia: Lippincot William \& Wilkins.

Wiederhold, et al. (2014). Virtual reality as a distraction technique in chronic pain patients. Cyberpsychology, Behavior and Social Networking, 17(6): 346352. DOI: $10.1089 /$ cyber.2014.0207

$\mathrm{Wu}$, et al. (2016). Lived experiences and illness representation of Taiwanese patients with late-stage chronic kidney disease. J Health Psychol, 21(12), 2788-2798

World Health Organization. (2010). Urbanization and health. Bull World Health Organ, 88, 245-246. doi:10.2471/BLT.10.010410

World Bank, W. D. I. (2016). Population ranking. Diakses dari http://databank.worldbank.org/data/do wnload/POP.pdf 